\title{
Infection of barramundi Lates calcarifer with Streptococcus iniae: effects of different routes of exposure
}

\author{
E. S. Bromage, L. Owens* \\ Discipline of Microbiology and Immunology, James Cook University, Townsville, Queensland 4811, Australia
}

\begin{abstract}
The use of various challenge techniques has allowed the formation of a hypothesis for the mode of infection of Streptococcus iniae in barramundi. A bacterial dose of $1 \times 10^{3}$ colony forming units (cfu), corresponding to the $\mathrm{LD}_{50}$, delivered orally to barramundi could initiate the sub-acute form of the disease observed at the farms. The acute form of the disease could be initiated through bath exposure to the pathogen. $S$. iniae was equally as infective in freshwater, saltwater or when fish were subject to skin trauma prior to exposure, with $\mathrm{LD}_{50}$ values of $3.2 \times 10^{4}, 2.0 \times 10^{4}, 3.2 \times 10^{4} \mathrm{cfu}$, respectively, when observed over a $10 \mathrm{~d}$ period. It is suggested that sub-acute infection occurs orally, with mass mortalities occurring through the increased presence of the bacterium in the environment.
\end{abstract}

KEY WORDS: Barramundi $\cdot$ Streptococcus iniae $\cdot$ Route of infection

Resale or republication not permitted without written consent of the publisher

\section{INTRODUCTION}

Streptococcus iniae has emerged globally to become one of the economically important bacterial infections in warm water aquaculture. It has been responsible for significant losses in Israel (Eldar et al. 1995, Zlotkin et al. 1998), Australia (Bromage et al. 1999) and America (Stoffregen et al. 1996, Perera et al. 1997, Bowser et al. 1998) in both fresh- and saltwater species. Barramundi Lates calcarifer is a euryhaline fish species cultured primarily throughout the tropics of Australia in floating cages, either in freshwater ponds or within tidal estuaries (Lobegeiger et al. 1998).

The culture of barramundi in marine cages has suffered severe losses due to Streptococcus iniae every summer since 1992. The bacterium is responsible for losses of between 8 and $15 \%$ of production per year, but in severe outbreaks it has resulted in losses of up to $70 \%$ of production (Bromage et al. 1999). There are 2 clinical forms of the disease observed: subacute and acute. The sub-acute form displays signs typical of streptococcal infections including exophthalmia, dark-

*Corresponding author. Email: leigh.owens@jcu.edu.au ened colouration and erratic swimming (Perera et al. 1998, Evans et al. 2000). However, this form of the disease is only responsible for about $1 \%$ of the losses observed. The acute form of the disease is the most devastating, with heavy losses occurring primarily overnight. There are limited clinical signs observed in fish dying of the acute form of the disease, with the only indication being mild corneal opacity in some cases. The only factor that alerts farmers to a pending outbreak comes from mortalities in rabbit fish Siganus spp. found co-habitating barramundi cages in the days before an outbreak, which is similar to the report of Zlotkin et al. (1998). In such cases, the isolation of $S$. iniae can be achieved primarily from the brain and spleen of both barramundi and Siganus spp. (Bromage 1997).

There is considerable conjecture in the literature about the portal of entry of streptococcal pathogens into susceptible hosts. Robinson \& Meyer (1966) were able to infect golden shiners Notemigonus crysoleucas by bathing them in a suspension of $10^{6}$ cells $\mathrm{ml}^{-1}$. The infective ability of a group-B streptococcal pathogen isolated by Rasheed \& Plumb (1984) was shown to dramatically increase when gulf killifish Fundulus grandis were subject to epidermal scarification prior to 
bacterial exposure by immersion. Taniguchi (1982) suggested that bacterial infection in cultured yellowtail Seriola quinquinradiata was occurring orally, through being fed infected trash fish. More recently, Evans et al. (2000) suggested that nares infection might be important to the establishment of the disease in striped bass Morone saxtilis.

These studies were all dependent on having high levels of Streptococcus iniae present in the environment for infection to take place. During preliminary research to determine the level of culturable $S$. iniae in the marine environment, it was found that the bacterium rarely reached numbers sufficient to become pathogenic to barramundi (Bromage 1997). This finding suggested that another mode of infection might be important. While barramundi culture relies on processed feeds, we hypothesized that the fish were becoming infected orally through the consumption of infected carrier fish or through the faecal-oral route. This study was devised to test the possible routes of entry of $S$. iniae into susceptible hosts in the marine environment, and to examine the potential of $S$. iniae as a pathogen of freshwater cultured barramundi.

\section{MATERIALS AND METHODS}

Fish selection and maintenance. Barramundi of $100 \pm 5 \mathrm{~mm}$ total length were obtained from a farm located outside the endemic area of the pathogen. All experimental trials were performed in $170 \mathrm{l}$ glass aquaria. Each aquarium was filled with seawater (35 parts per thousand, unless otherwise stated) and heated to $27^{\circ} \mathrm{C}$.

Preparation of bacterial inoculum. All studies were conducted with isolate number 28-97-L-K, isolated in a previous study and known to be pathogenic to barramundi (Bromage et al. 1999). The bacterial culture was grown for $24 \mathrm{~h}$ in brain-heart infusion broth (BHI, Oxoid) with continual shaking to provide bacteria in the exponential growth phase. The culture was pelleted by centrifugation $(4000 \times g)$ and washed 3 times in phosphate buffered saline (PBS) before being resuspended in PBS until an optical density of 1.0 was obtained at $A_{600}$ (absorbance at $600 \mathrm{~nm}$ wavelength), equating to viable bacterial count of $10^{8} \mathrm{cells} \mathrm{ml}^{-1}$. Successive serial 10-fold dilutions were performed in sterile PBS to obtain the range $10^{2}$ to $10^{7}$ colony forming units (cfu), and were validated by performing standard plate counts on the dilution series.

Experimental infection trials. Prior to exposure, fish were allowed to acclimatize for a period of $2 \mathrm{wk}$. The $\mathrm{LD}_{50}$ was determined for 5 different exposure routes: intraperitoneal, bath exposure (fresh- and saltwater), fish subjected to epidermal scarification (hereafter referred to as 'damaged') before bath exposure (saltwater), and oral infection. This was achieved by subjecting 10 fish to bacterial challenge at each of the 6 doses $\left(10^{2}\right.$ to $\left.10^{7} \mathrm{cfu}\right)$ for each of the modes of exposure described below.

Following the determination of the $\mathrm{LD}_{50}$, challenge trials were performed consisting of 3 groups of 10 fish for each of the methods of challenge at their respective $\mathrm{LD}_{50}$ dose.

Intraperitoneal injection. Fish were removed from the tank and placed in a $10 \mathrm{l}$ container of seawater. The ventral surface of the barramundi was swabbed with alcohol, and $0.1 \mathrm{ml}$ of the inoculum was injected into the intraperitoneal cavity of the barramundi using a $1 \mathrm{ml}$ syringe with a 25 gauge needle.

Bath exposure. Fish were removed from their tanks and placed into a $10 \mathrm{l}$ container of seawater or freshwater containing the appropriate dilutions of the bacteria. After an exposure period of $1 \mathrm{~min}$, the fish were removed and placed into their respective aquaria. Fish undergoing epidermal scarification were subjected to skin damage by removing scales over a $1 \mathrm{~cm}^{2}$ area, prior to bacterial bath exposure.

Oral exposure. Pelleted feed containing the bacteria was prepared as follows. A mixture containing $10 \% \mathrm{w} / \mathrm{v}$ gelatin was prepared and autoclaved. This was placed in a $40^{\circ} \mathrm{C}$ water bath for $2 \mathrm{~h}$ or until equilibrium was reached. Commercial feed pellets were then ground to a fine powder and mixed in with the gelatin at a rate of $20 \% \mathrm{w} / \mathrm{v}$. Pre-warmed sterile distilled water was added until the volume was equal to $45 \mathrm{ml}$ and thoroughly mixed until a homogenous mixture was formed. Five ml bacterial suspensions were made as described above and heated to $40^{\circ} \mathrm{C}$ in a water bath; this was then poured into the gelatin food mixture and thoroughly mixed. The resulting mixture was poured onto a tray to a depth of $10 \mathrm{~mm}$ and allowed to set. Once set, the mixture was cut into $1 \mathrm{~cm}^{2}$ cubes and fed to fish within $2 \mathrm{~h}$ of being made. Ten fish at each bacterial level were individually fed one infected pellet by placing them in individual tanks. They were then placed into $170 \mathrm{l}$ aquaria and mortalities reported. A tank of fish fed with an uninfected gelatin food mixture was used as a control. To ensure that the pellets were infected, a sample of 5 pellets from each level of bacteria was broken up into $9 \mathrm{ml}$ of sterile PBS and serial 10-fold dilution's were performed. A $100 \mu \mathrm{l}$ sample from a dilution level that would have approximated to a bacterial level of $10^{2}$ was placed onto blood agar (BA, Oxoid) supplemented with $5 \%$ sheep's blood and grown for $24 \mathrm{~h}$ to ensure that the bacteria were viable and at the desired level.

Controls. Controls were used for every method of exposure and consisted of 10 fish each which were subjected to identical handling procedures without being exposed to Streptococcus iniae. 
Survey of water for the presence of Streptococcus iniae. To determine if $S$. iniae could be cultured from the aquatic environment, 5 sites were sampled when an outbreak of $S$. iniae was occurring at the sea cage facility. Site 1 was located $4.5 \mathrm{~km}$ upstream in the estuary in which the fish were cultured; Site 2 was the farm; Site 3 was inside cages at the farm; Site 4 was located within $200 \mathrm{~m}$ of the farm at the mouth of the creek; and Site 5 was an oceanic site $4 \mathrm{~km}$ away from the farm. At each site, 10 water samples of $10 \mathrm{ml}$ were collected in sterile plastic containers and transported at ambient temperature back to the laboratory, where they were processed within $12 \mathrm{~h}$ of the sample being obtained using STAN/H media following the methods of Sakata \& Kawazu (1990). Where isolation of Streptococcus-like bacteria was made from individual water samples, sample colonies were biochemically characterised and numbers enumerated.

Survey of tank water and challenged fish faeces. During the process of the challenge trial, water and faeces samples were taken every day and subject to bacterial isolation and enumeration as described by Sakata \& Kawazu (1990). Briefly, 3 water samples were collected per tank $(10 \mathrm{ml})$, and faeces were collected via a fine mesh net and re-suspended in $10 \mathrm{ml}$ of sterile PBS. Successive serial 10-fold dilutions of the samples were performed and $0.1 \mathrm{ml}$ from each of the dilutions was spread on the agar plates.

Survey of the resident fish fauna for presence of Streptococcus iniae. During the harvest of barramundi at a second sea cage facility, a sample of other fish species found co-habiting in the barramundi cages was selected to undergo bacterial isolation. All fish were housed in separate $40 \mathrm{l}$ containers filled with aerated seawater and transported live to the laboratory, where bacterial isolation was performed from the brain, kidney and spleen.

Histopathology. The intestine, kidney, spleen, liver, heart, and brain obtained from experimentally infected and control fish were fixed in $10 \%$ neutral buffered formalin, embedded in paraffin and processed. Sec-

Table 1. Comparison of the observed mortality in barramundi via different routes of infection $(n=10)$. IP: intraperitoneal injection

\begin{tabular}{|cccccc|}
\hline Dose & IP & Oral & Damage & Saltwater & Freshwater \\
\hline $10^{7}$ & 10 & 10 & 10 & 10 & 10 \\
$10^{6}$ & 10 & 10 & 8 & 9 & 10 \\
$10^{5}$ & 9 & 10 & 7 & 6 & 6 \\
$10^{4}$ & 9 & 9 & 4 & 4 & 4 \\
$10^{3}$ & 4 & 5 & 1 & 1 & 2 \\
$10^{2}$ & 0 & 1 & 0 & 0 & 0 \\
$\mathrm{LD}_{50}$ & $2.0 \times 10^{3}$ & $1.0 \times 10^{3}$ & $3.2 \times 10^{4}$ & $3.2 \times 10^{4}$ & $2.0 \times 10^{4}$ \\
\hline
\end{tabular}

tions were stained with haematoxylin and eosin, Twort's modified Gram, and trichrome MSB, following standard procedures.

Data analysis. All data were plotted and examined to ensure statistical assumptions of normality were not violated. All statistical analyses were conducted using SPSS. Determination of the $\mathrm{LD}_{50}$ was conducted using probit analysis, and mortality schedules were compared using the survival function with pairwise comparison.

\section{RESULTS}

\section{Exposure trials}

Streptococcus iniae was highly effective at causing mortality at low challenge doses irrespective of the route of exposure (Table 1). The method resulting in the lowest $\mathrm{LD}_{50}$ was determined to be oral infection $\left(1.0 \times 10^{3}\right.$ $\mathrm{cfu}$ ) when observed over a $10 \mathrm{~d}$ period. Little variation was observed between the infective levels $\left(\mathrm{LD}_{50}\right)$ required for freshwater, saltwater, or damaged bath exposure with 2.0 to $3.2 \times 10^{4} \mathrm{cfu} \mathrm{ml}^{-1}$ needed for mortality.

\section{Intraperitoneal injection}

Delivery of the bacterium via intraperitoneal injection consistently resulted in mortalities within the first 48 h. Clinical signs were limited to corneal opacity. Histologically, bacteria were present in all organs except the intestine; minimal pathological signs were observed.

\section{Bath exposure and trauma}

Pathogen exposure via freshwater, saltwater or after skin trauma resulted in high mortalities in the first $48 \mathrm{~h}$ (up to $50 \%$ ). No mortality was observed after Day 7 (Fig. 1). Clinical signs were more pronounced than with intraperitoneal injection, with exophthalmia, corneal opacity, and ascitic fluid accumulation in the peritoneal cavity present in all fish dying from exposure. Bacteria were observed in all organs examined, both histologically and via bacterial culture. No bacteria were observed histologically or were able to be cultured from the surviving fish.

\section{Oral exposure}

The onset of signs of disease was delayed when the pathogen was administered orally, with the first 


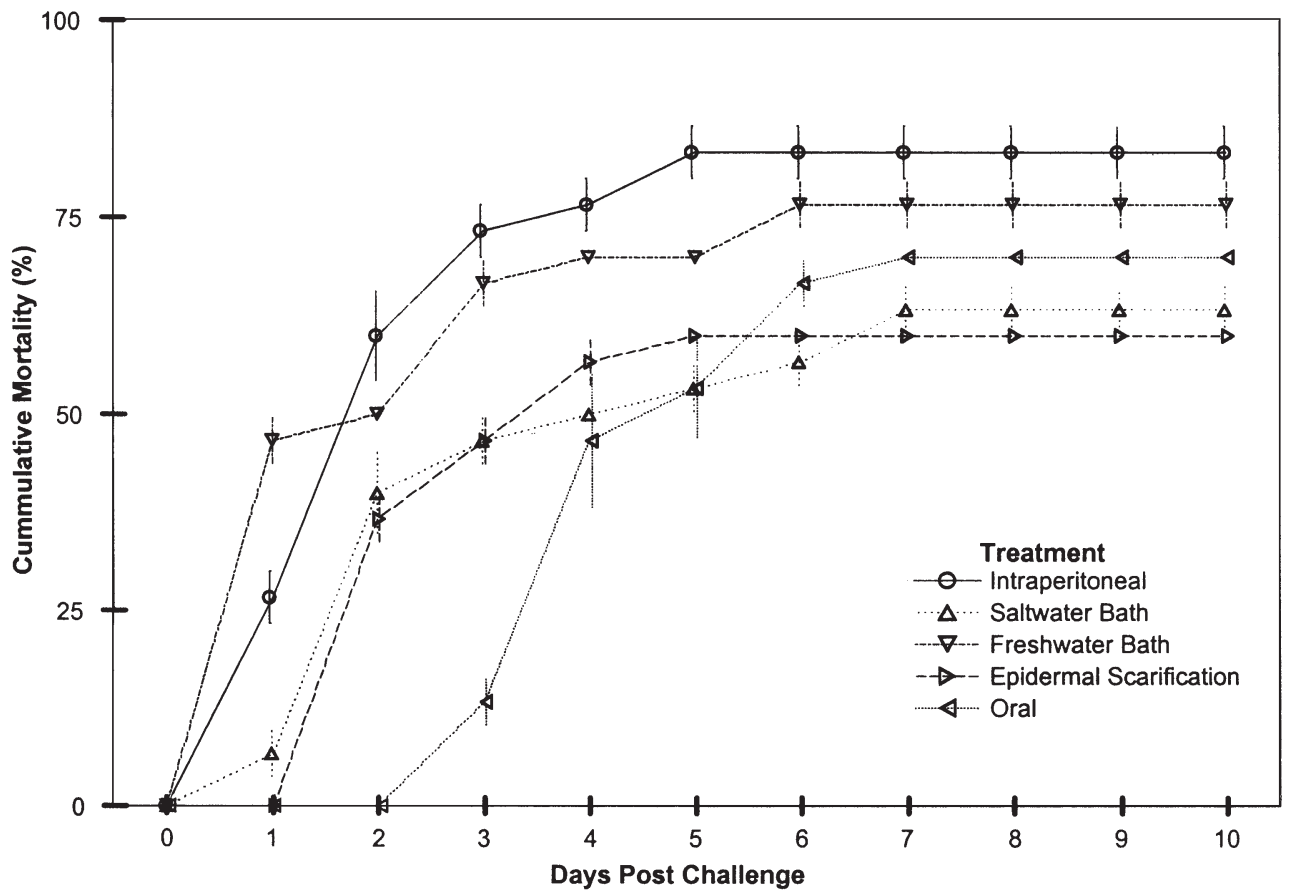

Fig. 1. Cumulative mortality in barramundi exposed to an infective dose of Streptococcus iniae via various infection routes. All values are means $\pm \operatorname{SE}(n=30)$ symptoms occurring on Day 2 and the first deaths on Day 3. The mortality schedule of oral delivery was the only route of infection statistically different with pairwise comparison to intraperitoneal injection $(G=4.30$, $\mathrm{df}=1, \mathrm{p}<0.05$ ), indicating a possible difference in the progress of the disease. No deaths were observed after Day 7. All fish displayed exophthalmia, corneal opacity and in severe cases complete necrosis of the eye. Often the fish swam in a spiraling fashion. Grampositive bacteria were observed in every organ, especially the brain and intestine of those fish dying within the experimental timeframe and infrequently from those surviving challenge. Histopathological findings were the most severe in orally infected fish with large amounts of fibrin deposition observed in the spleen and brain, indicating disseminated intravascular coagulation (DIC). The heart often displayed an invasion of mononuclear inflammatory cells, mainly consisting of macrophages. Within the kidney, the tubular epithelial cells displayed evidence of cloudy swelling and hyaline droplet degeneration. The main pathological finding was severe acute suppurative meningitis and ventriculitis present in all moribund fish. Bacterialaden proteinaeous fluid surrounded by an inflammatory exudate was present within the brain of infected fish and signified the possibility of cranial oedema. No histopathological findings were observed in the controls.
Bacterial isolation from dead and moribund fish resulted in pure cultures of Streptococcus iniae from the brain, kidney and spleen. The bacterium was not isolated from the spleen or kidney of the surviving fish on Day 10. However, pure cultures of $S$. iniae were infrequently isolated from the brain and intestine of the survivors of oral challenge. No mortalities occurred in any of the control fish and the bacterium was not recovered from any organ.

\section{Water sampling}

Water sampling was performed at the peak of high tide; water temperature was $27^{\circ} \mathrm{C}$ and the salinity 36 ppt. The results from water testing at the various sites are shown in Table 2. The sites located away from the farm yielded numbers of Streptococcus iniae below that which could be enumerated by our methods $(1 \times$

Table 2. Streptococcus iniae. Presence at 5 aquatic sites located at or near an aquaculture facility

\begin{tabular}{|lccc|}
\hline Location & $\begin{array}{c}\text { Water } \\
\text { samples (n) }\end{array}$ & $\begin{array}{c}\text { Positive } \\
\text { samples (n) }\end{array}$ & $\begin{array}{c}\text { Count } \\
\text { (mean } \pm \text { SD) }\end{array}$ \\
\hline Site 1: Upper estuary & 10 & 0 & $<10^{2}$ \\
Site 2: Farm & 10 & 9 & $2.3 \times 10^{4}\left( \pm 1.2 \times 10^{2}\right)$ \\
Site 3: Farm (inside cage) & 10 & 10 & $1.1 \times 10^{5}\left( \pm 5.7 \times 10^{2}\right)$ \\
Site 4: Mouth of estuary & 10 & 0 & $<10^{2}$ \\
Site 5: Oceanic & 10 & 0 & $<10^{2}$ \\
\hline
\end{tabular}


Table 3. Streptococcus iniae. Relative isolation from various fish found cohabiting the barramundi cages

\begin{tabular}{|lcc|}
\hline Species of fish & Fish tested & Isolation of S. iniae \\
\hline Rabbit fish Siganus spp. & 12 & 10 \\
Puffer fish Arothron hispidus & 8 & 5 \\
Silver bream Acanthopagrus australis & 4 & 2 \\
Gold spot cod Epinephalis tauvina & 2 & 2 \\
Barramundi cod Cromileptes altivelis & 1 & 1 \\
Trevally Caranx ignobilis & 1 & 0 \\
Coral trout Plectropomus leopardus & 1 & 0 \\
\hline
\end{tabular}

freshwater tilapia ponds, at bacterial concentrations demonstrated to be pathogenic to barramundi via waterborne exposure.

The results from this study indicate that artificial challenge with Streptococcus iniae can cause morbidity and mortality in barramundi at very low bacterial numbers, independent of the mode of delivery. Furthermore, the challenge methods used in this study instigated both the acute and sub-acute forms of the disease in artificially challenged fish that are

$10^{2} \mathrm{cfu} \mathrm{ml}^{-1}$ ). Sampling from Sites 2 and 3 resulted in the isolation of $S$. iniae above our detection limit in 90 and $100 \%$ of the samples, respectively.

\section{Tank water and faeces}

Streptococcus iniae was unable to be cultured from the faeces or tank water of intraperitoneally challenged fish. The tank water containing fish exposed via saltwater bath, including those subject to trauma, was below detectable limits. However, $S$. iniae was often isolated from the faeces after Day 3, up to Day 7. $S$. iniae could be isolated from both the tank water and faeces of fish subject to oral and freshwater challenge methods.

\section{Resident fish}

Streptococcus iniae was isolated consistently from rabbit fish Siganus spp., and puffers Arothron hispidus. Other fish including silver bream Acanthopagrus australis, gold spot cod Epinephalis tauvina and barramundi cod Cromileptes altivelis were all found to be positive for the presence of $S$. iniae. Isolation of $S$. iniae was not possible from single samples taken from either trevally Caranx ignobilis or coral trout Plectropomus leopardus (Table 3).

\section{DISCUSSION}

While the primary environmental source of Streptococcus iniae is still to be determined, this study indicated that fish found co-habiting the barramundi enclosures may serve as an important reservoir of the bacterium. This was further highlighted by the inability to culture $S$. iniae from the water away from the influence of the farm. However, water sampling close to the farm resulted in numbers of Streptococci similar to those reported by Sakata \& Kawazu (1990) in observed in naturally infected fish. When the bacterium was delivered intraperitoneally or by bath exposure, high levels of mortality were observed within the first $48 \mathrm{~h}$. Rapid mortalities occurring after exposure to Streptococcus spp. have been reported from other experimentally infected fish (Boomker et al. 1979, Minami et al. 1979). Foo et al. (1985) reported a similar pattern in the outbreak of streptococcosis in cultured rabbit fish, where fish died rapidly before showing any clinical signs of the disease. Fish surviving past the acute mortality stage were seen to gradually develop more pronounced clinical disease signs, especially in orally challenged fish. The most obvious sign observed was when the fish swam in a spiraling fashion. This particular behavior has previously been attributed to central nervous system damage (Eldar et al. 1994).

The general histological findings observed in challenged fish were similar to previous reports of streptococcal infections (Miyazaki et al. 1984, Eldar et al. 1995, Bowser et al. 1998), with fish exhibiting a mixed inflammatory infiltrate in the liver, kidney and heart. Moderate to severe epicarditis was often observed. The affected fish were found to be suffering from acute suppurative bacterial meningitis. There were also large volumes of inflammatory exudate surrounding the bacteria-laden proteinaeous fluid located within the sub-arachnoid spaces of the brain. The presence of suppurative inflammation indicates that the infection has progressed to a stage where the defense mechanisms are rendered largely ineffective (Sleigh et al. 1992).

An unusual finding was the presence of fibrin in the microcirculation of many organs in the infected animals. Fibrin deposition has previously been reported to occur in the liver and spleen of naturally infected tilapia (Miyazaki et al. 1984). Barramundi in this experiment often displayed severe disseminated intra-vascular coagulation, indicated by fibrin deposition in the microcirculation of the brain and spleen.

The presence of disseminated intra-vascular coagulation has previously been attributed to the activation 
of the immune system by potent exotoxins that can be produced by many bacterial species, including streptococci (Lindop et al. 1992). Many streptococci, which are pathogens of fish, can produce an array of toxins (Kimura \& Kusuda 1979, 1982). Kusuda \& Hamaguchi $(1988,1989)$ demonstrated that both intra- and extracellular toxins could cause death in yellowtail Seriola quinqueradiata, within 10 to $34 \mathrm{~h}$. Further evidence from histology supports the hypothesis of toxin production. Hyaline droplet degeneration is known to occur from the absorption of excessive amounts of proteinaceous substances, such as bacterial toxins (Hibiya 1982). The inflammation observed in the liver and heart has previously been attributed to invasive bacteria, which produce exotoxins (Sleigh et al. 1992). Clearly, there is considerable histological evidence that Streptococcus iniae is producing a toxin which may be important in the progress of the disease, and needs further investigation.

Freshwater barramundi culture has increased significantly in the last few years (Lobegeiger et al. 1998). This study indicates that freshwater barramundi could be highly susceptible to Streptococcus iniae at low bacterial doses. This is in agreement with other published reports where $S$. iniae was indicated as a primary pathogen of freshwater cultured species (e.g. Eldar et al. 1994, Perera et al. 1994, Stoffregen et al. 1996, Bowser et al. 1998).

It was hypothesised that damage to the integument may predispose barramundi to streptococcal infection. However, epidermal scarification did not appear to enhance the pathogens ability to enter its host when compared to bath-inoculated fish. Trauma prior to bath challenge did not increase mortalities over non-traumatized fish (Table 1, Fig. 1). This finding suggests that sites of injury are not important for the entry of Streptococcus iniae into barramundi. This result is in contrast to the findings of Rasheed \& Plumb (1984) and Foo et al. (1985), who suggested that integumental injury is an important predisposing factor to streptococcosis in gulf killifish and rabbit fish, respectively.

Most significant was the ability of low Streptococcus iniae numbers to infect barramundi per os. Compared to the other routes, the disease signs were delayed between 2 and 3 d. However, once symptoms appeared, the mortality was rapid, with death usually occurring within 24 to $48 \mathrm{~h}$ of the first clinical signs. Taniguchi (1982a,b, 1983) recognized the importance of food-borne infection to yellowtail. These results led to more efficient handling of food and lowering the overall incidence of disease. Shoemaker et al. (2000) also suggested that cannibalisation of infected fish may have been responsible for the spread of $S$. iniae in experimentally challenged tilapia. Kusuda \& Kimura (1978) found high numbers of bacteria in the intestine of infected fish $72 \mathrm{~h}$ after challenge, even when all other organs were clear of the pathogen. This indicated that in addition to the brain, the intestine represented a haven for $S$. iniae. This is supported by the current study, where $S$. iniae persisted the intestine of artificially challenged barramundi up to $10 \mathrm{~d}$ after oral challenge. Furthermore, the presence of the bacterium in the intestine allowed a direct avenue for release of the pathogen into the water via the fishes' excrement.

It is proposed that the initial infection of barramundi occurs orally through susceptible fish ingesting infected carrier fish or through the faecal-oral route. This results in the sub-acute infection in the population, which is observed at the farms as numerous fish swimming near the surface of the water. As the number of infected fish rise, so does the level of Streptococcus iniae released into the environment, reaching levels that would cause acute epizootics initiated through waterborne exposure. The highly virulent nature of $S$. iniae and its ability to cause significant production losses in culture situations highlights the need for efficient control strategies. If indeed the primary mode of infection is through oral exposure, management practices such as minimizing feral fish inside sea cages by using more effective barrier netting, diligent removal of moribund fish, and the reduction in stocking densities may help control the disease.

\section{LITERATURE CITED}

Boomker J, Imes G, Cameron C, Naude T, Schoonbee H (1979) Trout mortalities as a result of Streptococcus infection. Onderstepoort J Vet Res 46:71-77.

Bowser P, Wooster G, Getchell R (1998) Streptococcus iniae infection of tilapia Oreochromis niloticus in a recirculation production facility. J World Aquacult Soc 29:335-339

Bromage E (1997) Streptococcus iniae, a bacterial infection in barramundi, Lates calcarifer. Honours thesis, James Cook University, Townsville

Bromage E, Thomas A, Owens L (1999) Streptococcus iniae, a bacterial infection in barramundi Lates calcarifer. Dis Aquat Org 36:177-181

Eldar A, Bejerano Y, Bercovier H (1994) Streptococcus shiloi and Streptococcus difficile: two new streptococcal species causing a meningoencephalitis in fish. Curr Microbiol 28: $139-143$

Eldar A, Bejerano Y, Livoff A, Horovitcz A, Bercovier H (1995) Experimental streptococcal meningo-encephalitis in cultured fish. Vet Microbiol 43:33-40

Evans J, Shoemaker C, Klesius P (2000) Experimental Streptococcus iniae infection of hybrid striped bass (Morone chrysops $\times$ Morone saxatilis) and tilapia (Oreochromis niloticus) by nares inoculation. Aquaculture 189:197-210

Foo J, Ho B, Lam T (1985) Mass mortality in Siganus canaliculatus due to streptococcal infection. Aquaculture 49: 185-195

Hibiya T (1982) An atlas of fish histology, normal and pathological features. Gustav Fisher Verlag, Stuttgart

Kimura H , Kusuda R (1979) Studies on the pathogenesis of streptococcal infection in cultured yellowtials Seriola spp.: 
effect of the cell free culture on experimental streptococcal infection. J Fish Dis 2:501-510

Kimura H, Kusuda R (1982) Studies on the pathogenesis of streptococcal infection in cultured yellowtails, Seriola spp.: effect of crude exotoxin fractions from cell-free culture on experimental streptococcal infection. J Fish Dis 5:471-478

Kusuda R, Hamaguchi M (1988) Extracellular and intracellular toxins of Streptococcus sp. isolated from yellowtail. Bull Eur Assoc Fish Pathol 8:9-10

Kusuda R, Hamaguchi M (1989) Determination of the median lethal dose of cell-associated toxins from Streptococcus sp. in the yellowtail, Seriola quinqueradiata. Bull Eur Assoc Fish Pathol 9:117-118.

Kusuda R, Kimura H (1978) Studies on the pathogenesis of streptococcal infection in cultured yellowtails Seriola spp.: the fate of Streptococcus sp. bacteria after inoculation. J Fish Dis 1:109-114

Lindop GBM, Percy-Robb IW, Walker ID (1992) Disturbances of body fluids, haemostasis and the flow of blood. In: MacSween RNM, Whaley K (eds) Muir's textbook of pathology, 13th edn. Edward Arnold, London, p 73-111

Lobegeiger R, Gillespie J, Duncan P, Taylor-Moore N (1998) Aquaculture in Queensland. In: Proc Queensland Warmwater Aquaculture Conference (Status and Potential). Aquaculture Information Technologies, Tarome, p 13-48

Minami T, Nakamura M, Ikeda Y, Ozaki H (1979) A BetaHemolytic Streptococcus isolated from cultured yellowtail. Fish Pathol 14:33-38

Miyazaki T, Kubota S, Kaige N, Miyashita T (1984) A histopathological study of streptococcal disease in tilapia. Fish Pathol 19:167-172

Perera R, Johnson S, Collins M, Lewis D (1994) Streptococcus iniae associated with mortality of Tilapia nilotica $\times T$. aurea hybrids. J Aquat Anim Health 6:35-340

Perera R, Johnson S, Lewis D (1997) Epizootiological aspects

Editorial responsibility: David Bruno,

Aberdeen, Scotland, UK of Streptococcus iniae affecting tilapia in Texas. Aquaculture 152:25-33

Perera R, Fiske R, Johnson S (1998) Histopathology of hybrid tilapias infected with a biotype of Streptococcus iniae. J Aquat Anim Health 10:294-299

Rasheed V, Plumb J (1984) Pathogenicity of a non-haemolytic group B Streptococcus sp. in gulf killifish (Fundulus grandis Baird and Girard). Aquaculture 37:97-105

Robinson J, Meyer F (1966) Streptococcal fish pathogen. J Bacteriol 92:512

Sakata T, Kawazu T (1990) Isolation of Streptococci from fish and aquatic environments. Mem Fac Fish Kagoshima Univ 39:151-157

Shoemaker C, Evans J, Klesius P (2000) Density and dose: factors affecting mortality of Streptococcus iniae infected tilapia (Oreochromis niloticus). Aquaculture 188:229-235

Sleigh RM, Pennington TH, Lucas SB (1992) Microbial infections. In: MacSween RNM, Whaley K (eds) Muir's textbook of pathology, 13th edn. Edward Arnold, London, p 279-337

Stoffregen D, Backman S, Perham R, Bowser P, Babish J (1996) Initial disease report of Streptococcus iniae infection in hybrid striped (sunshine) bass and successful therapeutic intervention with the fluoroquinolone antibacterial enrofloxacin. J World Aquacult Soc 27:420-434

Taniguchi M (1982a) Experiment on peroral inoculation via food to induce yellowtail streptococcicosis. Bull Jpn Soc Sci Fish 48:1717-1720

Taniguchi M (1982b) Influence of food condition on artificial peroral infection of yellowtail streptococcicosis. Bull Jpn Soc Sci Fish 48:1721-1723

Taniguchi M (1983) Progress of streptococcicosis of yellowtail in peroral inoculation. Bull Jpn Soc Sci Fish 49:1171-1174

Zlotkin A, Hershko H, Eldar A (1998) Possible transmission of Streptococcus iniae from wild fish to cultured marine fish. Appl Environ Microbiol 64:4065-4067

Submitted: March 25, 2002; Accepted: July 19, 2002

Proofs received from author(s): November 11, 2002 